\title{
New insights into the anchorage zones of precast pretensioned concrete girders
}

\author{
Kizzy Van Meirvenne ${ }^{a}$, Wouter De Corte ${ }^{b}$, Veerle Boel ${ }^{c}$, Luc Taerwe ${ }^{d}$ \\ Department of Structural Engineering, Ghent University, Belgium \\ aKizzy.Vanmeirvenne@UGent.be, bWouter.Decorte@UGent.be, Veerle.Boel@UGent.be, \\ dLuc.Taerwe@UGent.be
}

Keywords: Pretensioned girders, End zones, FEM, Abaqus

\begin{abstract}
Pretensioned concrete girders are widely used in the construction sector. Nevertheless, optimisation is still possible considering the end zones. These end zones are subject to different types of stress due to the local transmission of the prestress force. In order to optimise these regions, a 3D non-linear finite element model was developed using the Abaqus software. Different from other attempts, a full scale girder with multiple strands is modelled. The accuracy of the FE model was verified by comparing the numerical results with experimental data. A full scale test in a precast concrete plant during normal production is carried out, and a good fit between the experimental and numerical results is obtained. Finally, the model was used to design a girder without end block. The calculation of the additional reinforcement was based on vector plots of the tensile stresses, extracted from the FEM.
\end{abstract}

\section{Introduction}

During the production of a prestensioned concrete girder, the prestress force is transferred from the prestressed strands to the surrounding concrete. This leads to different types of stresses, such as spalling, splitting and bursting, in the anchorage zone [1]. Specific reinforcement is needed to avoid the appearance of cracks or to limit their width. Currently, linear models and strut-and-tie models are used to calculate the additional reinforcement, despite the fact that these models are not accurate enough. Okumus et al. [2] investigated the anchorage zones of deep wide-flanged prestressed girders and proved that this issue can be addressed by using non-linear finite element models (FEM). In this research, a FEM of a full-scale girder with end block and multiple strands is developed. The transfer of the prestress force is modeled by defining friction based interaction properties between the strands and the surrounding concrete. This modeling procedure is based on the principles of Arab et al. [3] and Abdelatif et al. [4], but extended to a larger sample with multiple strands. A first validation of the developed FEM is performed by monitoring the modeled full-size girder in a precast concrete plant during normal production. For the prestress transfer, a very good agreement between the numerical and experimental results is obtained. Consequently, it can be assumed that this is a promising model which overall predicts the stresses in a reliable manner. However, during the experimental test as well as for the numerical results, no cracks were observed. For this reason, this FEM is used to analyze the stresses in the same girder but without end block. Hereby, the main challenge is the estimation and limitation of the crack sizes. Okumus et al. [2] predict only the location of the cracks and this by visualizing the principal tensile strains, whereas Abdelatif et al. [4] use the principal plastic tensile strains. In addition, according to Chaudhari et al. [5] the mesh size also plays a vital role in predicting the stresses in the concrete damage plasticity material model, which is used in this FEM. So, it seems that only the crack location and the direction of the crack opening can be predicted, but not the crack width. In this paper a possible way to estimate the crack width is examined, based on the relation between the concrete tensile stress and the crack width. From this theory, an appropriate reinforcement design is developed to minimize the appearance of cracks in the proposed girder. 


\section{Finite element model}

A 3D non-linear finite element model was created using the Abaqus finite element software (Fig. 1). The concrete shape as well as the prestressed strand and the additional reinforcement were simulated in the software. In order to lower the computing time, only one fourth of the girder was actually modelled. The passive reinforcement elements are embedded in the concrete girder elements, and interaction properties were defined between the concrete element and the prestressing strands. Both interaction properties in tangential and normal direction are implemented as the Coulomb friction law was used to define the frictional behaviour. The pretension force in the strands was specified by means of a predefined field. Furthermore, material models for both concrete and steel were implemented. Steel was modelled as a linear material because the stress in the strands and in the stirrups will not reach the yield stress, and the concrete damage plasticity (CDP) model is used to define the material model for concrete. This model is based on the Drucker-Prager hypothesis and is an appropriate model to simulate the nonlinear behaviour of concrete in compression and tension. Besides general material properties, the CDP model requires several specific input parameters to define the compressive and tensile behavior. Because this FEM will be compared with an experimental test, the compressive and tensile parameters are partially based on concrete samples at the moment the strands are released as well as at 21 days. The compressive concrete strength was based on the results of the concrete samples, whereas the tensile strength was calculated using the conversion formulas of the fib Model Code [1].

\section{Experimental tests}

In order to validate the numerical model, an experimental test has been executed in a concrete precast plant during normal production. A full-scale girder, 3.75 meter in length and pretensioned with 10 seven wire strands $(3 / 8 ", 1 / 2 "$ and $5 \mathrm{~mm})$ is produced. The I-shaped cross-section has a height of $600 \mathrm{~mm}$, a width of $350 \mathrm{~mm}$ and both ends were provided with an end block of $600 \mathrm{~mm}$. An transition zone of $200 \mathrm{~mm}$ was foreseen between the rectangular and I-shaped section. The end blocks closest to the point of release is provided with a minimum reinforcement, consisting of three rectangular stirrups with a diameter of $8 \mathrm{~mm}$ every $250 \mathrm{~mm}$, followed by two rectangular stirrups in the transition zone, whereas in the other end block no stirrups were placed. The girder is cast with a self-compacting concrete C55/67. Furthermore, the beam is instrumented with DEMEC measurement points (Fig. 2). Before and shortly after the prestress release, vertical and horizontal strains at the concrete cover were measured with a mechanical strain gauge with a basis of $100 \mathrm{~mm}$ and a 16 microstrain resolution.

\section{Comparison of analytical results with experimental data}

In order to validate the FEM, the experimental results are compared with the numerical results extracted from Abaqus. Because concrete is a mixture consisting of several components which results in a scatter on the material properties which, in turn, influences the various input parameters and consequently the outcome of the finite element models, a parametric study was conducted. The coefficient of friction, the fracture energy, the modulus of elasticity and the tensile strength of concrete were investigated as influencing parameters. The outcome of the investigation is the importance of the concrete tensile strength and the friction coefficient. A friction coefficient between 0.8 and 1.0 turns out to result in good fits between the experimental and numerical results. In the following section the results obtained for this girder without end block are discussed, based on a concrete tensile strength of $3.18 \mathrm{MPa}$ and a friction coefficient equal to 1 .

\section{Girder without end block}

In this configuration, the end zone is equipped with a minimum amount of I-shaped stirrups with a diameter of $8 \mathrm{~mm}$ every $250 \mathrm{~mm}$. The formation of cracks is visible in two regions, based on the maximum principal strains exceeding the strain levels at the tensile strength (Fig. 3). The first region is situated in the web near the end face of the girder. These cracks are caused by the spalling effect. The second region, on the contrary, is situated at the transition from the bottom flange to the web and is caused by shear transfer. 


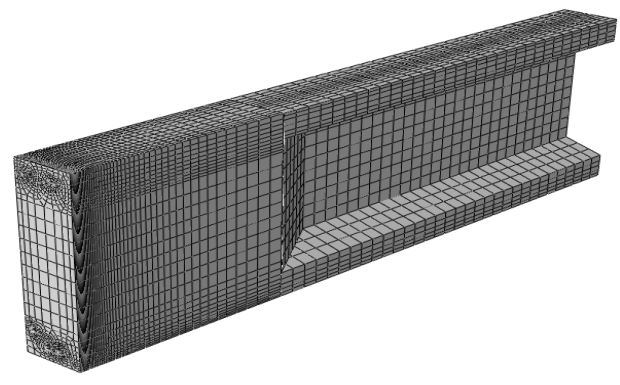

Fig. 1 FEM in Abaqus

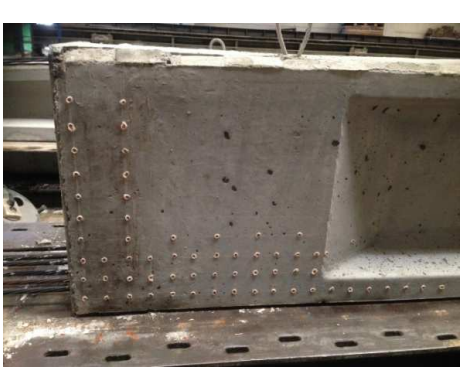

Fig. 2 DEMEC measuring points
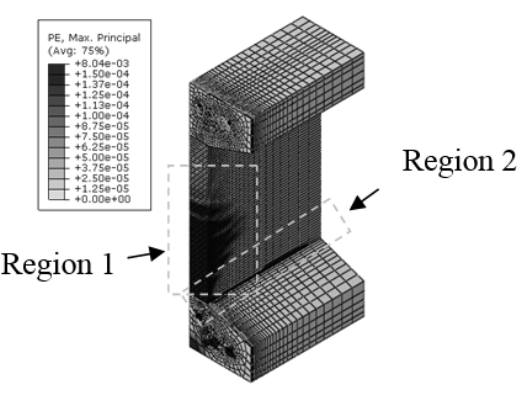

Fig. 3 Location of the cracks in the FE model

In the FEM, the prestress force in the strands increases in different steps until the total force is applied. When analysing these different steps in the anchorage zone, it is clearly visible that the vertical tensile stresses in the concrete first increase until the tensile strength of $3.18 \mathrm{MPa}$ is reached (at $29.5 \%$ of the total prestress force) and thereafter decrease. This phenomenon is visible in fig. 4a, where the percentages refer to the fraction of the total prestress force. This decrease of the tensile stress in the anchorage zone points to the formation of cracks. After the maximum tensile stress is reached, the stresses decrease until $2.87 \mathrm{MPa}$ in region 1 (fig. $4 \mathrm{~b}$ ) and $2.45 \mathrm{MPa}$ in region 2.

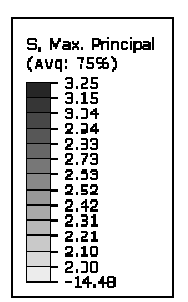

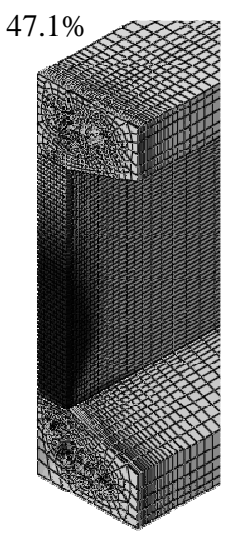
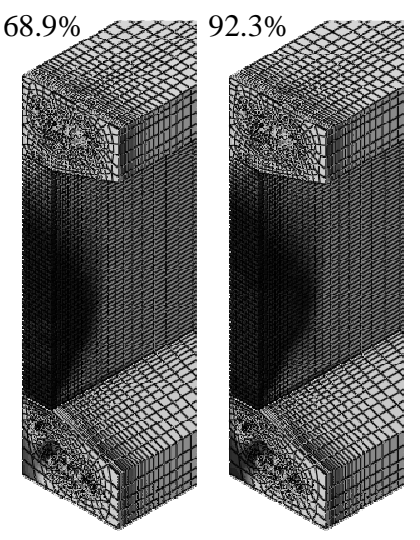

Fig. 4a Principal tensile stresses in the end zone
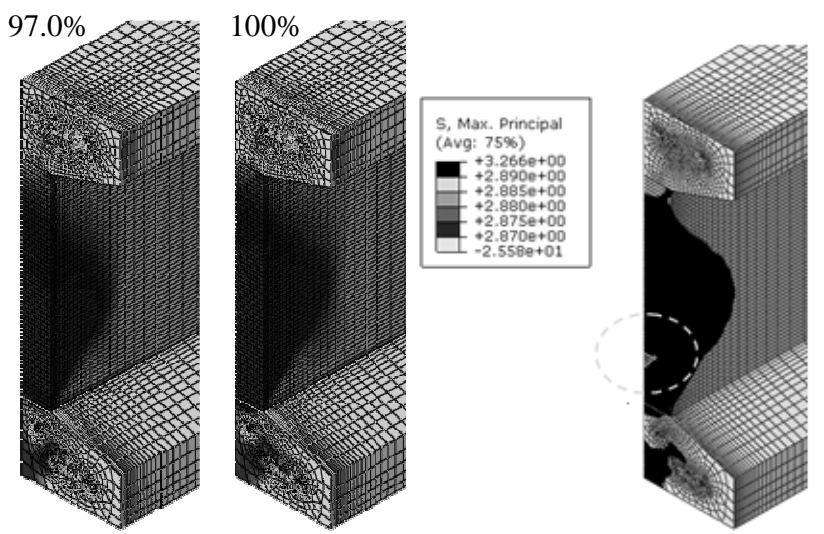

Fig. $4 \mathrm{~b}$ Decrease of the stress after full prestressing

Because at this moment only the crack location can be detected, a method to estimate the crack width is proposed, based on the observation that the decrease of the tensile stress can be related to the crack width since one of the input parameters of the concrete material model in Abaqus is the relationship between the concrete tensile stress and the crack opening (Fig. 5). According to Eurocode 2 [6] the crack width must be limited to $0.2 \mathrm{~mm}$, which means that tensile stresses may decrease until 0.11 $\mathrm{MPa}$. Since such a large decrease seems not to be an acceptable value., a crack width of $0.02 \mathrm{~mm}$ $(10 \%)$ and $0.005 \mathrm{~mm}$ (barely visible) were proposed as limit values in this paper. This results in a stress decrease to $2.1 \mathrm{MPa}$ and $2.9 \mathrm{MPa}$ respectively. Since the aim is a design without visible cracks, a limit of $2.9 \mathrm{MPa}$ has been applied to develop an appropriate reinforcement configuration. Although this seems to be a straightforward method, the results very much depend on the uncertainties concerning the relation between the concrete tensile stress and the crack width. This relation should be experimentally tested and improved for the specific case of end zone reinforcement.

In order to design the most adequate reinforcement configuration, the vectors of the tensile stresses in the end zones are analysed (fig. 6). As Fig. 4 already showed, there are 2 regions where cracks occur. As expected, these zones are also visible in the vector plot, where the length of the vector is related to the magnitude of the maximum principal stresses. Near the end face of the girder the vectors are almost vertical, which indicates spalling stresses. In order to limit spalling cracks, additional reinforcement bars close the the end of the girder have to be placed. In the second region, 
the vectors have an inclination which is clarified by the arrow on the figure. This is due to the fact that the strands are situated in the botom flange of the girder only, which necessitates the prestressing force to be introduced in the web through stress transfer between the flange and the web. Different reinforcement configurations are modelled, and of these the most optimal configuration is presented in Fig. 7 and consist of 5 vertical reinforcement bars with a diameter of $8 \mathrm{~mm}$ every $30 \mathrm{~mm}$ and Ashaped inclined reinforcement bars with a diameter of $10 \mathrm{~mm}$ between the flange and the web. In this model the concrete tensile stresses decrease until $2.96 \mathrm{MPa}$ and the area extent of the cracked zone is much smaller. The predefined requirements with respect to the crack width are fulfilled.
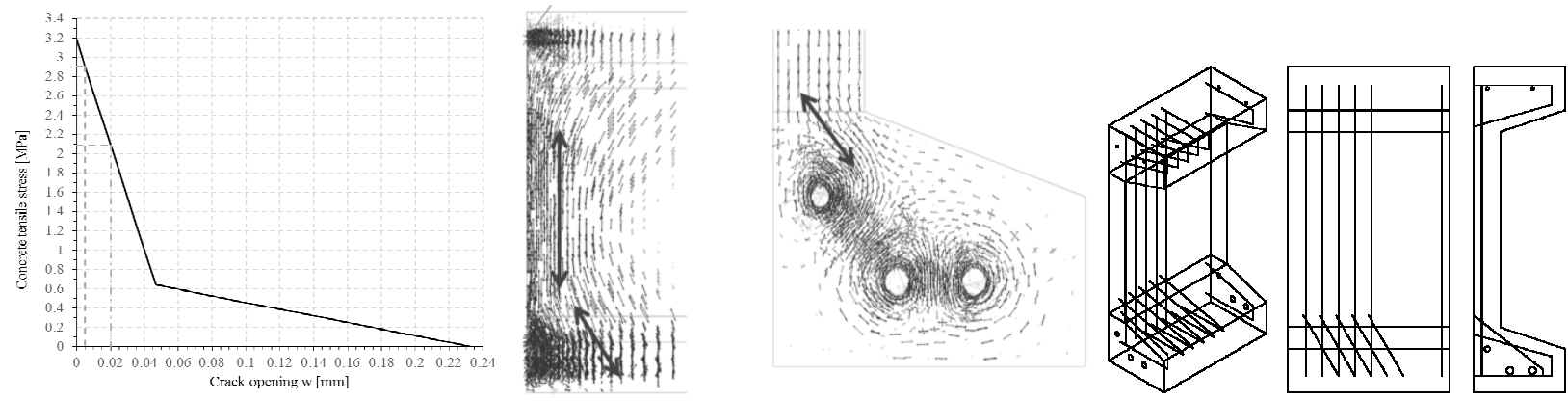

Fig. 5 Relation concrete tensile stress and crack opening Fig. 6 Vectors of the tensile stresses Fig. 7 Optimized reinforcement

\section{Conclusion}

A 3D non-linear finite element model is developed to predict stresses in the end zone in a reliable way. It is used to analyze the stresses in a girder without end block. Hereby, the main challenge is the estimation of the actual crack width, not directly rendered by the CDP material model. In this paper a possible way to estimate the crack width is examined, which is based on the relation between the concrete tensile stress and the crack width. Although it seems an appropriate method, it requires further verification. Furthermore, two regions in the end zone where cracks appear are identified. By a number of adaptations to the traditional I-shaped stirrups, the end block could be omitted maintaining acceptable crack formation. Further research is required to optimize the end zones and the required amount of reinforcement. Additional validations of the current model are required before design formulas can be derived.

\section{References}

[1] Comité-Euro-International du Béton, Model Code 2010, Lausanne: Fib, 2011.

[2] P. Okumus, M. Oliva en S. Becker, „Nonlinear finite element modeling of cracking at ends of pretensioned bridge girders," Engineering Structures, pp. 267-275, 2012.

[3] A.A. Arab, S.S. Badie, M.T. Manzani, „A methodological approach for finite element modeling of pretensioned concrete members at the release of pretensioning," Engineering Structures, nr. 33, pp. 1918-1929, 2011.

[4] A. Abdelatif, J. Owen en M. Hussein, „Modelling the prestress transfer in pre-tensioned concrete elements," Finite Elements in Analysis and Design, pp. 47-63, 2015.

[5] S.V.Chaudhari, M.A.Chakrabarti, „Modeling of concrete for nonlinear analysis Using Finite Element Code ABAQUS," International Journal of Computer Applications, Volume 44- No.7

[6] CEN. Eurocode 2: Design of concrete structures - Part 1-1: "General rules and rules for buildings. European Standard EN 1992-1-1:2004:," Comité Européen de Normalisation, Brussels, 2004. 